\title{
Cancers after hematopoietic cell transplantation for aplastic anemia-the importance of persistence
}

(c) The Author(s), under exclusive licence to Springer Nature Limited 2021

Bone Marrow Transplantation (2022) 57:152-153; https://doi.org/ 10.1038/s41409-021-01514-4

Prognosis of patients with Severe Aplastic Anemia (SAA) treated with hematopoietic cell transplantation (HCT) has improved considerably; however, long-term morbidity, particularly the occurrence of secondary cancer remains of high concern [1]. Previous studies investigating subsequent cancers after HCT were mainly performed on patients transplanted for a malignant disease. These studies showed that irradiation, either as part of the pre-transplant treatment or as part of the conditioning, is the most unfavorable risk factor $[2,3]$. Consequently, SAA patients have for decades been conditioned with regimens including cyclophosphamide with or without antithymocyte globulin (ATG), excluding total body irradiation. The identification of further risk factors for subsequent cancers has frequently been hampered by reduced size of SAA patient's cohorts and/or the heterogeneity of the treatment modality.

In this issue of Bone Marrow Transplantation, Phuong Vo et al. [4] from the Fred Hutchinson Cancer Research Center analyzed subsequent cancers in 329 patients with SAA given HLA-matched related marrow grafts. The cohort was extremely homogenous in terms of conditioning regimen (cyclophosphamide \pm ATG), source of hematopoietic stem cells (bone marrow) and prevention of graft-vs-host disease (GVHD) (methotrexate \pm cyclosporine), and the study covered a long follow-up with a median of 26 years (range 1-47). In this cohort the authors identified 53 cancers in 46 patients, 42 with solid tumors and 4 with blood cancers, and they showed a cumulative incidence of subsequent cancers at 26 years of $11 \%$, and $7 \%$ when non-melanoma skin cancers were excluded. Overall, there was a 2.03-fold excess of cancers when compared to a matched non-transplanted US population. Among them, tumors of the oropharyngeal cavity represented a remarkable proportion, being 13.63-fold higher than expected. The observed subsequent cancers had a late onset as nearly all developed between 14 and 34 years after $\mathrm{HCT}$, and chronic GVHD was significantly associated with skin and oropharyngeal cancers (Fig. 1).

To improve the outcome of HCT, important changes have been attempted over the last decades, these modifications concern mainly the type of donor, stem cell source, conditioning regimen, and prevention of GVHD. Although innovation is necessary, the interpretation of such changes may be particularly hazardous in rare diseases with small patients' cohorts, as it is the case for SAA. Furthermore, for the evaluation of long-term complications covering several decades, retrospective studies are needed. For such long-term analysis, the consistency of treatment strategy over time is of significant importance. The strengths of the present study are the homogeneity of the study cohort and the treatment strategy used over a remarkable long follow-up. Indeed, the extreme consistency in using HLA-matched related donors, bone marrow as stem cell source and similar conditioning and GVHD prophylaxis over nearly 4 decades increases greatly the importance of the results.

An important but not unexpected finding of this study was the negative prognostic value of chronic GVHD for the development of skin and oropharyngeal cancers, with an overall cumulative incidence of cancer at 26 years of $16.65 \%$ among patients with chronic GVHD, compared to $8.71 \%$ for patients without chronic GVHD. This is consistent with previous reports $[5,6]$, which demonstrated that skin and oropharyngeal cancers often occurred at sites previously affected by chronic GVHD and less frequently at sites with active GVHD. GVHD is one of the most important causes of morbidity and mortality postHCT. While some malignant diseases might benefit from graft-versus leukemia/lymphoma effect, this is not the case for SAA. This data shows that in addition to the deleterious effect of GVHD during the early phase of $\mathrm{HCT}, \mathrm{GVHD}$ is also associated with late occurring subsequent cancers in SAA patients.

This study revealed some unexpected relevant findings. Firstly, considering the type of used conditioning, without any radiation, we would expect a low risk for subsequent thyroid and breast cancer $[7,8]$. The results of this study show indeed only one thyroid cancer in the whole cohort, but there were 7 breast cancers in 139 transplanted females, thus showing a significant excess of observed breast cancers in relation to what was expected (SIR 2.50; $p=0.05$ ). These findings, suggesting that factors other than radiation would have an influence on the development of breast cancer, require confirmation in further cohorts and, if confirmed, the actual recommendations for longterm survivorship in respect of breast cancer risk should be accordingly adapted [9].

Secondly, the three factors which may potentially affect the immune system, i.e. GVHD prophylaxis with cyclosporine/methotrexate (compared to methotrexate alone), conditioning including ATG (compared to no ATG), as well as preceding immunosuppressive therapy (IST) before HCT were associated individually with a higher but not significant incidence of subsequent cancers. These findings suggest that immunomodulation might have an impact on the development of subsequent tumors in SAA receiving $\mathrm{HCT}$, although none of the mentioned factors shows individually enough statistical power. Strikingly, in this study, cancers appeared late and at a time point where all patients were no longer treated with immunosuppressive medication.

Another interesting finding is the donor type myelodysplastic syndromes (MDS) found in two patients. The authors in the paper extensively discussed the underlying mechanisms that are possibly involved with the occurrence of this complication. Among additional hypothesis, the disease itself may play a possible role, and a family predisposition for malignant diseases could be considered. In a review on donor cell leukemia which included 64 reported cases, $11 \%$ were observed in aplastic anemia patients [10], which is a rather high proportion considering that SAA patients treated with $\mathrm{HCT}$ represent about $3-5 \%$ of all transplants [11]. A defective marrow stromal/microenvironment 


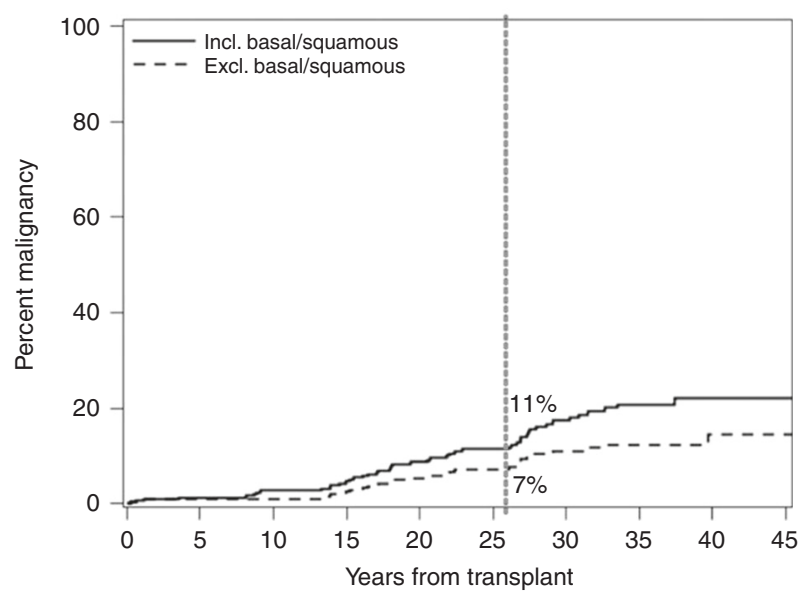

Fig. 1 The cumulative incidence of all observed subsequent cancers. This figure demonstrates the late appearance of subsequent cancers and the continuous increase of their cumulative incidence over 4 decades. Phuong Vo et al. BMT 2021.

has been described as a cofactor in the pathogenesis of SAA [12] explaining partly the late evolution of a SAA treated with IST to a MDS. Furthermore, since all donors of the cohort were relatives, an undetected family predisposition for bone marrow failure might be involved. It is certainly relevant to point out that bone marrow failures can have cryptic forms in their presentation, and may first appear as late as the 4 th or 5 th decade of life.

Finally, the late appearance of second cancers in SAA patients treated with HCT as well as the continuing appearance of cancers even 45 years after transplantation (Fig. 1), supports the recommendation of life-long specialized follow-up also for SAA patients. SAA patients receiving HCT are often young, so it is particularly important insisting on long-term surveillance.

With this study, the authors have contributed notably with robust evidence in the field of HCT for SAA.

Alicia Rovó ${ }^{1 \mathrm{~m}}{ }^{凶}$ and André Tichelli ${ }^{2}$ ${ }^{1}$ INSELSPITAL, Department of Hematology and Central Hematology Laboratory, Bern University Hospital, Bern, Switzerland. ${ }^{2}$ Hematology, University Hospital, Basel, Switzerland. ${ }^{\bowtie}$ email: alicia.rovo@insel.ch

\section{REFERENCES}

1. Socie G, Henry-Amar M, Bacigalupo A, Hows J, Tichelli A, Ljungman P, et al. Malignant tumors occurring after treatment of aplastic anemia. European Bone Marrow Transplantation-Severe Aplastic Anaemia Working Party. N. Engl J Med. 1993;329:1152-7.

2. Curtis RE, Rowlings PA, Deeg HJ, Shriner DA, Socie G, Travis LB, et al. Solid cancers after bone marrow transplantation. N. Engl J Med. 1997;336:897-904.
3. Rizzo JD, Curtis RE, Socie G, Sobocinski KA, Gilbert E, Landgren O, et al. Solid cancers after allogeneic hematopoietic cell transplantation. Blood. 2009;113:1175-83.

4. Vo P, Onstad L, Flowers ME, Storb R. Cancers after HLA-matched related bone marrow transplantation for aplastic anemia. Bone Marrow Transplant. 2021. https://doi.org/10.1038/s41409-021-01498-1.

5. DePry JL, Vyas R, Lazarus HM, Caimi PF, Gerstenblith MR, Bordeaux JS. Cutaneous malignant neoplasms in hematopoietic cell transplant recipients: a systematic review. JAMA Dermatol. 2015;151:775-82.

6. Curtis RE, Metayer C, Rizzo JD, Socie G, Sobocinski KA, Flowers ME, et al. Impact of chronic GVHD therapy on the development of squamous-cell cancers after hematopoietic stem-cell transplantation: an international case-control study. Blood. 2005;105:3802-11.

7. Friedman DL, Rovo A, Leisenring W, Locasciulli A, Flowers ME, Tichelli $A$, et al. Increased risk of breast cancer among survivors of allogeneic hematopoietic cell transplantation: a report from the FHCRC and the EBMT-Late Effect Working Party. Blood. 2008;111:939-44.

8. Cohen A, Rovelli A, Merlo DF, van Lint MT, Lanino E, Bresters D, et al. Risk for secondary thyroid carcinoma after hematopoietic stem-cell transplantation: an EBMT Late Effects Working Party Study. J Clin Oncol: Off J Am Soc Clin Oncol. 2007;25:2449-54.

9. Majhail NS, Rizzo JD, Lee SJ, Aljurf M, Atsuta Y, Bonfim C, et al. Recommended screening and preventive practices for long-term survivors after hematopoietic cell transplantation. Bone Marrow Transplant. 2012;47:337-41.

10. Wiseman DH. Donor cell leukemia: a review. Biol Blood Marrow Transplant. 2011;17:771-89.

11. Passweg JR, Baldomero H, Basak GW, Chabannon C, Corbacioglu S, Duarte R, et al. The EBMT activity survey report 2017: a focus on allogeneic HCT for nonmalignant indications and on the use of non-HCT cell therapies. Bone marrow Transplant. 2019;54:1575-85.

12. Balderman SR, Calvi LM. Biology of BM failure syndromes: role of microenvironment and niches. Hematol Am Soc Hematol Educ Program. 2014;2014:71-6.

\section{AUTHOR CONTRIBUTIONS}

Design of editorial manuscript: AR and AT, literature search, interpretation of literature, writing of manuscript: AR and AT. Both authors have read and agreed with the content of this manuscript.

\section{COMPETING INTERESTS}

AR received research funding from Novartis, Alexion, CSL Behring, she has acted as a consultant, taken part in advisory boards, and received honoraria from Novartis, Alexion, Bristol Myers Squibb, AstraZeneca, OrPha Swiss and Swedish Orphan Biovitrum AG. AT has nothing to disclose.

\section{ADDITIONAL INFORMATION}

Correspondence and requests for materials should be addressed to Alicia Rovó.

Reprints and permission information is available at http://www.nature.com/ reprints

Publisher's note Springer Nature remains neutral with regard to jurisdictional claims in published maps and institutional affiliations. 